doi: 10.32620/oikit.2019.83.11

УДК 519.714.7

В. Ф. Сенчуков, Т. В. Денисова

\title{
Мінімізація булевих функцій за номерами наборів значень аргументів
}

\section{Харківський національний економічний університет імені Семена Кузнеця}

Пропонується оригінальний підхід до аналітичної канонічної мінімізації перемикальних (булевих) функцій, основою якого є подання булевих функцій (БФ) у вигляді функції однієї змінної - номера набору $v$ значень її аргументів. Для цього залученням функції Антьє встановлюється залежність (у вигляді фрормул) значень кожної з $n$ змінних від номера $v$. Для побудови мінімальної диз'юнктивної або кон'юнктивної нормальної форми БФ відштовхуються від відповідних досконалих форм. У зв'язку з цим виникає потреба в описуванні послідовності номерів наборів, на яких змінні набувають значень 1 і 0 . Загальні члени таких послідовностей можуть бути отримані за допомогою фрормули загального члена числової послідовності в поданні через скінченні різниці її членів. Далі встановлюється зв'язок між сумою значень атомів (терм) $\sigma(v)$ з номерами їх значень. За допомогою значень $\sigma(v)$ вирішується питання про склеювання конституент одиниці або нуля. Для БФ від трьох і чотирьох змінних подаються відповідно тривимірний і чотиривимірний куби, вершини яких помічено сигмами. Оскільки необхідна умова склеювання конституент - модуль різниці між сигмами дорівнює одиниці - не є достатньою, то використовується критерій склеювання: конституенти одиниці або нуля склеюються тоді і тільки тоді, коли відстань Гаммінга між двома значеннями $\sigma(v)$ дорівнює одиниці. На підставі описаних засобів отримано загальний порядок склеювання конституент одиниці або нуля. Для побудови тупикових форм використовується матриця розміру $m \times n$, де $m$ - кількість простих імплікант або імпліцент, $n$ - кількість наборів $v$, на яких БФ набуває одиничних або нульових значень; подаються вони не буквами, а наборами одиниць i нулів, які їм відповідають. Запропонований підхід до мінімізації БФ названо методом V-мінімізації. Наведено приклад мінімізації БФ від п'яти змінних, заданої номерами наборів $v$ значень її аргументів, на яких вона набуває значень, що дорівнюють одиниці, тобто - із властивістю $f=1$. Обговорено можливість застосування $v$-мінімізації БФ у базисах, відмінних від базису $\left(\wedge, \vee,{ }^{-}\right)$, і на перспективу - застосування до мінімізації БФ цілочислового математичного програмування.

Ключові слова: булева функція, метод мінімізації, набір, операція, поглинання, склеювання, скорочена форма, тупикова фрорма.

\section{Вступ}

Мінімізація булевих функцій широко використовується у проектуванні цифрових пристроїв, що дає змогу отримувати рекомендації для побудови економічних схем цифрових автоматів. Усі відомі методи мінімізації детально висвітлено в роботах [1; 2], де наведено джерела літературних посилань. До недоліків існуючих методів слід віднести утруднення реалізації, якщо функція має не менше п'яти аргументів. Запропонований метод, названий методом v-мінімізації, при належному програмному забезпеченні обчислювальних пристроїв - EOM дає можливість уникнути технічних труднощів під час його реалізації.

\section{1. Булева функція як функція номера набору значень їі аргументів}

Нехай $f\left(x_{1}, x_{2}, \ldots, x_{n}\right)$ - задана булева функція (БФ) $n$ змінних, а $v$ номер набору значень змінних як зображення в десятковій системі числення кор- 
тежів із нулів та одиниць: $v=0,2^{n}-1$. Наприклад, для $n=3$ (табл. 1) кортежам зліва направо в четвертому стовпці відповідають десяткові числа від нуля до семи. У п'ятому стовпці наведено значення істинності БФ трьох змінних.

Спочатку встановимо залежність значень змінних $x_{i}, i=\overline{1, n}$ від номера $v$, для чого проаналізуємо відповідні послідовності для $n=3$. Значеннями $x_{1} €$ послідовність нулів та одиниць з періодом $T=2$, значеннями $x_{2}-$ послідовність з періодом $T=2^{2}: 0011$, а значеннями $x_{3}$ - послідовність з періодом $T=2^{3}$.

Залежність значень аргументів від номера $v$ описується формулами, які виводяться за допомогою базисних індикаторів числових послідовностей - нескінченновимірних векторів, координатами яких $є$ нулі й одиниці, Таблиця 1 Набори значень змінних, їх номери та значення самої БФ

\begin{tabular}{|c|c|c|c|c|}
\hline$x_{3}$ & $x_{2}$ & $x_{1}$ & $v$ & $f$ \\
\hline 0 & 0 & 0 & 0 & 0 \\
\hline 0 & 0 & 1 & 1 & 0 \\
\hline 0 & 1 & 0 & 2 & 1 \\
\hline 0 & 1 & 1 & 3 & 1 \\
\hline 1 & 0 & 0 & 4 & 0 \\
\hline 1 & 0 & 1 & 5 & 1 \\
\hline 1 & 1 & 0 & 6 & 0 \\
\hline 1 & 1 & 1 & 7 & 1 \\
\hline
\end{tabular}
які з періодом $T$-повторюються [3]:

$$
e_{i}(v, T)=\left[\frac{v-(i-1)}{T}\right]-\left[\frac{v-(i-2)}{T}\right], i=1,2,3, \ldots, T, v=0,1,2,3, \ldots .
$$

Якщо в (1) до зменшуваного і від'ємника додати одиницю, то отримаємо інший варіант цієї формули:

$$
e_{i}(v, T)=\left[\frac{v+T-i+1}{T}\right]-\left[\frac{v+T-i+2}{T}\right] .
$$

Наприклад, для $T=2$ маємо:

$$
\begin{gathered}
e_{1}(v, 2)=\left[\frac{v}{2}\right]-\left[\frac{v-1}{2}\right]=(1,0,1,0,1,0, \ldots), \\
e_{2}(v, 2)=\left[\frac{v+1}{2}\right]-\left[\frac{v}{2}\right]=(0,1,0,1,0,1, \ldots) .
\end{gathered}
$$

Описом $x_{1}(v) \in$ послідовність $e_{2}(v, 2)$. Ії̈ можна отримати й із $e_{1}(v, 2)$ :

$$
x_{1}(v)=1-e_{1}(v, 2)=\left[\frac{v+1}{2}\right]-\left[\frac{v}{2}\right] .
$$

Аналогічно знаходимо:

$$
x_{2}(v)=\left[\frac{v+2}{4}\right]-\left[\frac{v}{4}\right] ; \quad x_{3}(v)=\left[\frac{v+4}{8}\right]-\left[\frac{v}{8}\right] .
$$

Узагальнювальна формула для БФ від $n$ змінних $f\left(x_{1}, x_{2}, \ldots, x_{n}\right)$, коли $T=2^{i}, i=\overline{1, n}$, має вигляд:

$$
x_{i}(v)=\left[\frac{v+2^{i-1}}{2^{i}}\right]-\left[\frac{v}{2^{i}}\right] ; i=\overline{1, n}, v=\overline{0,2^{n}-1} .
$$

3 урахуванням співвідношень (3) отримуємо:

$$
f\left(x_{1}, x_{2}, \ldots, x_{n}\right)=\left|x_{i}=x_{i}(v), i=\overline{1, n}\right|=f\left(x_{1}(v), x_{2}(v), \ldots, x_{n}(v)\right)=F(v)-
$$

БФ як функція номера набору значень її аргументів. 
БФ від трьох змінних із табл. 1 має вигляд:

$$
f\left(x_{1}, x_{2}, x_{3}\right)=F(v)=\left[\frac{v+6}{8}\right]-\left[\frac{v+4}{8}\right]+\left[\frac{v+3}{8}\right]-\left[\frac{v+2}{8}\right]+\left[\frac{v+1}{8}\right] \text {. }
$$

На наборах $v=2,3,5,7$ вона набуває значень, що дорівнюють одиниці, а на наборах $v=0,1,4,6-$ нулю.

Якщо нумерацію змінних здійснювати не справа наліво, а навпаки, то формула (3) виглядатиме так:

$$
x_{i}(v)=\left[\frac{v+2^{n-i}}{2^{n-i+1}}\right]-\left[\frac{v}{2^{n-i+1}}\right]
$$

і тоді для $n=3$ дістанемо:

$$
x_{1}(v)=\left[\frac{v+4}{8}\right]-\left[\frac{v}{8}\right], \quad x_{2}(v)=\left[\frac{v+2}{4}\right]-\left[\frac{v}{4}\right], \quad x_{3}(v)=\left[\frac{v+1}{2}\right]-\left[\frac{v}{2}\right] .
$$

Перевагу слід віддати нумерації змінних справа наліво (див. табл. 1), адже показник степеня $2^{i}$ у знаменниках дробів під знаком Антьє $є$ простішим, ніж у степеня $2^{n-i+1}$. Ця обставина є суттєвою, якщо йдеться про написання програм для реалізації відповідних формул на комп'ютері.

\section{2. Послідовності номерів наборів змінних, які набувають значень 1 і 0}

Задача канонічної мінімізації БФ аналітичним способом потребує її спрощення з метою отримання диз'юнктивної або кон'юнктивної нормальної форми (ДНФ, КНФ), яка містить найменшу кількість букв. Для цього до досконалих нормальних форм БФ застосовують операції поглинання та неповного склеювання (метод Квайна - Мак-Класкі) або операції узагальненого склеювання до ДНФ або КНФ (метод Блейка). Порівняно з методом Квайна метод Квайна - МакКласкі стосовно склеювання потребує меншої кількості попарних порівнянь. Це забезпечується, за ідеєю Мак-Класкі, розбиттям двійкових номерів наборів змінних на групи.

Наприклад, для $n=4$ набори за кількістю одиниць охоплюються групами:

- нульова: 0000;

- перша: 0001, 0010, 0100, 1000;

- друга: 0011, 0110, 1001;

- третя: 0111, 1011;

- четверта: 1111.

Зіставляючи сусідні групи, проводимо їх склеювання. Так, нульова й перша групи в результаті дають такі набори: $000-, 00-0,0-00,-000$, де прочерк ставиться на місці змінної, за якою проводиться склеювання. Аналогічно для інших сусідніх груп.

Знайдемо загальні члени послідовностей номерів наборів $v$, на яких $x_{i}$ набувають значень 1 (для ДНФ) і 0 (для КНФ), залучаючи формулу загального члена числової послідовності через скінченні різниці ії членів:

$$
S(n)=S(1)+\sum_{i=1}^{n-1} d_{i} \text {, де } d_{i}=S(i+1)-S(i)-\text { скінченні різниці. }
$$


Через $v_{i}^{1}(v)$ позначимо підпослідовності номерів $v$, що описують значення змінних $x_{i}$, які дорівнюють одиниці, залежно від номера набора. Візуальний аналіз табл. 1 показує, що значення $x_{i}$ повторюються з періодом $T_{i}=2^{i-1}$. Для $x_{1}$ маємо:

$$
v_{1}^{1}(v)=(1,3,5,7,9, \ldots)=2 v+1, \quad v_{1}^{0}(v)=(0,2,4,6,8, \ldots)=2 v .
$$

Зважаючи на періодичність повторення одиниць і нулів, запишемо загальну формулу $v_{i}^{1}(v)-$ для всіх змінних:

$$
v_{i}^{1}(v)=v+2^{i-1}+2^{i-1}\left[\frac{v}{2^{i-1}}\right] \text {, }
$$

де третій доданок здійснює стрибок до наступного періоду за умови, що $v=2^{i-1}$.

Остаточно подамо формулу для $v_{i}^{1}(v)$ у вигляді:

$$
\begin{gathered}
v_{i}^{1}(v)=2^{i-1}\left(1+\left[\frac{v}{2^{i-1}}\right]\right)+v, \\
i=\overline{1, n}, \quad v=0,2^{i-1}-1 .
\end{gathered}
$$

Послідовності $v_{i}^{0}(v)$, що описують значення змінних $x_{i}$, які дорівнюють нулеві, не потребують окремого доведення, оскільки вони є логічними доповненнями [3] послідовностей $v_{i}^{1}(v): v_{i}^{0}(v)=\overline{v_{i}^{1}(v)}$, і навпаки.

Наведемо відповідні підпослідовності номерів $v_{i}^{1}(v), v_{i}^{0}(v)$ для $n=4$, тобто для $i=1,2,3,4$ (табл. 2):

$$
\begin{gathered}
v_{1}^{0}(v)=(0,2,4,6,8, \ldots)=2 v, \\
v_{1}^{1}(v)=(1,3,5,7,9, \ldots)=2 v+1 ; \\
v_{2}^{1}(v)=(2,3,6,7,10, \ldots)=(4 v+2,4 v+3), \\
v_{2}^{0}(v)=(0,1,4,5,8,9, \ldots)=(4 v, 4 v+1) ; \\
v_{3}^{1}(v)=(4,5,6,7,12,13,14,15,20, \ldots)=(8 v+4,8 v+5,8 v+6,8 v+7), \\
\quad v_{3}^{0}(v)=(0,1,2,3,8,9,10,11,16, \ldots)=(8 v, 8 v+1,8 v+2,8 v+3) ; \\
v_{4}^{1}(v)=(8,9,10, \ldots, 14,15,24, \ldots)=(16 v+8,16 v+9, \ldots, 16 v+14,16 v+15), \\
v_{4}^{0}(v)=(0,1,2,3,4,5,6,7,16, \ldots)=(16 v, 16 v+1, \ldots, 16 v+6,16 v+7) .
\end{gathered}
$$

Таблиця 2

Кортежі значень змінних і відповідні їм номери

\begin{tabular}{|c|c|c|c|c|c|}
\hline$x_{4}$ & $x_{3}$ & $x_{2}$ & $x_{1}$ & $v$ & $\sigma_{v}$ \\
\hline 0 & 0 & 0 & 0 & 0 & 0 \\
\hline 0 & 0 & 0 & 1 & 1 & 1 \\
\hline 0 & 0 & 1 & 0 & 2 & 1 \\
\hline 0 & 0 & 1 & 1 & 3 & 2 \\
\hline 0 & 1 & 0 & 0 & 4 & 1 \\
\hline 0 & 1 & 0 & 1 & 5 & 2 \\
\hline 0 & 1 & 1 & 0 & 6 & 2 \\
\hline 0 & 1 & 1 & 1 & 7 & 3 \\
\hline 1 & 0 & 0 & 0 & 8 & 1 \\
\hline 1 & 0 & 0 & 1 & 9 & 2 \\
\hline 1 & 0 & 1 & 0 & 10 & 2 \\
\hline 1 & 0 & 1 & 1 & 11 & 3 \\
\hline 1 & 1 & 0 & 0 & 12 & 2 \\
\hline 1 & 1 & 0 & 1 & 13 & 3 \\
\hline 1 & 1 & 1 & 0 & 14 & 3 \\
\hline 1 & 1 & 1 & 1 & 15 & 4 \\
\hline
\end{tabular}


Для кожного $i=\overline{1, n}$ і кожного $v=\overline{0,2^{i}-1}$ послідовності $v_{i}^{1}(v)$ і $v_{i}^{0}(v)$ у сукупності описують відрізок послідовності натуральних чисел, починаючи з нуля до $2^{n}-1$, i, разом з тим, повну систему лишків за модулем $2^{n}$. Як бачимо, послідовності $v_{i}^{1}(v)$ і $v_{i}^{0}(v) €$ узагальненими арифметичними прогресіями (у. а. п.) [4] з періодами $T_{i}=2^{i-1}, D_{i}=2^{i}$, де $i=\overline{1, n}$. Якщо $n=1$, то маємо арифрметичну прогресію: $T_{1}=1, D_{1}=2$.

\section{3. Зв'язок суми значень атомів із номером їх наборів}

Задача мінімізації БФ аналітичним способом потребує її спрощення з метою отримання диз'юнктивної або кон'юнктивної нормальної форми (ДНФ, КНФ), яка містить найменшу кількість букв-змінних (канонічна мінімізація), або фрормули, яка містить найменшу кількість логічних операцій (загальна мінімізація).

Як уже зазначалося, для цього застосовуються операції поглинання та неповного склеювання до досконалих нормальних форм БФ (метод Квайна Мак-Класкі) або операції узагальненого склеювання до ДНФ або КНФ (метод Блейка). Конституенти одиниці $\left(c_{v}^{1}\right)$ і конституенти нуля $\left(c_{v}^{0}\right)$ склеюються за умови, що набори значень атомів відрізняються значенням лише одного атома. Наприклад, для $n=3$ конституенти $c_{4}^{1}=(100)$ і $c_{5}^{1}=(101)$ склеюються за змінною $x_{1}$. Аналогічно для конституент нуля.

Уведемо до розгляду суму значень аргументів (атомів) для кожного номера набору $v$ :

$$
\sigma_{v}=\sigma(v)=\sum_{i=1}^{n} x_{i}(v)
$$

На графрі геометричного способу подання БФ від трьох змінних (рис. 1) показано $\sigma(v)$ для $v=\overline{0,7}$.

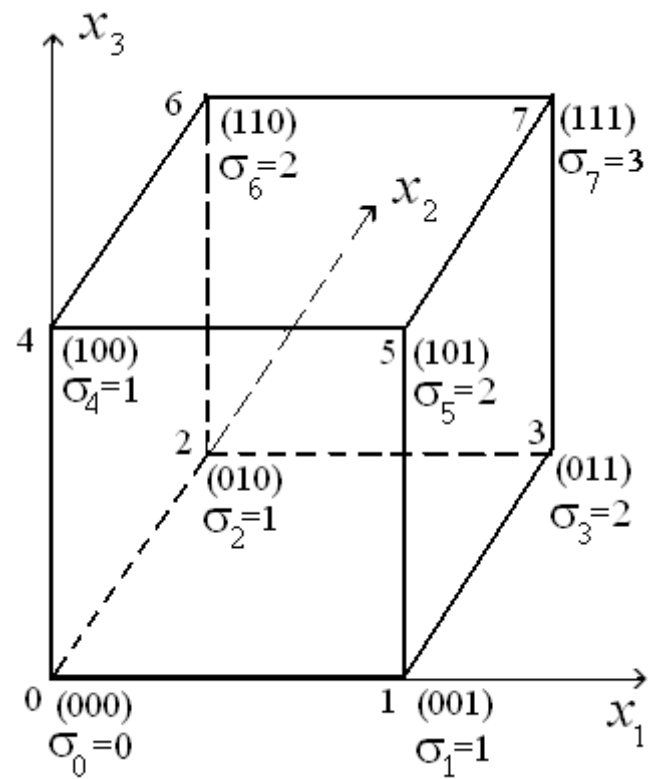

Рис. 1. Граф тривимірного куба

Щоб задати БФ, позначають (жирними точками або зірочками) вершини куба, які відповідають наборам вартостей аргументів, на яких БФ набуває значення 1.

Вершини куба відповідають конституентам одиниці - це терми третього рангу, ребра - добутку двох атомів (у прямому або інверсному вигляді) це терми другого рангу, грані - одній змінній - це терми першого рангу.

За допомогою значень $\sigma(v)$ вирішується питання про склеювання конституент одиниці або нуля. 
Теорема 1 (необхідна умова склеювання конституент). Якщо конституенти одиниці $c_{v}^{1}$ або нуля $c_{v}^{0}$ склеюються, то модуль різниці сум $\sigma_{i}$ і $\sigma_{j}$ дорівнює одиниці:

$$
c_{i}^{1} \uparrow c_{j}^{1}\left(c_{i}^{0} \uparrow c_{j}^{0}\right) \Rightarrow\left|\sigma_{i}-\sigma_{j}\right|=1,
$$

де $\uparrow$ - символ склеювання, $i, j \in\left\{0,1, \ldots, 2^{n}-1\right\}$.

Доведення. Справедливість співвідношення (8) випливає з означень понять "конституента" і "склеювання".

Наведена умова не є достатньою. Наприклад, $c_{1}^{1}=(001)$ і $c_{6}^{1}=(110)$ не склеюються, хоча умова (8) для них виконується (див. рис. 1).

Достатня умова потребує використання відстані Гаммінга [5] між двома двійковими векторами як кількості однойменних координат векторів, які не збігаються, тобто $\left|x_{k}^{1} \neq x_{k}^{0}\right|$, де $k \in\{1,2, \ldots, n\},|\cdot|$-.символ кількості.

Теорема 2 (критерій склеювання конституент $c_{v}^{1}$ або $c_{v}^{0}$ ). Конституенти одиниці або нуля склеюються тоді і тільки тоді, коли відстань Гаммінга між двома значеннями $\sigma(v)$ дорівнює одиниці:

$$
c_{i}^{1} \uparrow c_{j}^{1} \quad\left(c_{i}^{0} \uparrow c_{j}^{0}\right) \Leftrightarrow d_{H}\left(\sigma_{i}, \sigma_{j}\right)=1,
$$

де $\uparrow$ - символ склеювання;

$d_{H}\left(\sigma_{i}, \sigma_{j}\right)$ - відстань Гаммінга між наборами з номерами $i, j$, яким відповідають суми $\sigma_{i}, \sigma_{j}, i, j \in\left\{0,1, \ldots, 2^{n}-1\right\}$.

Доведення. Справедливість співвідношення (9) випливає з означень понять "склеювання" і "відстань Гаммінга".

Якщо взяти, наприклад, функцію з табл. 1:

\begin{tabular}{|c|c|c|c|c|c|c|c|c|}
\hline$v$ & 0 & 1 & 2 & 3 & 4 & 5 & 6 & 7 \\
\hline$f(v)$ & 0 & 0 & 1 & 1 & 0 & 1 & 0 & 1 \\
\hline$\sigma(v)$ & & & 1 & 2 & & 2 & & 3 \\
\hline
\end{tabular}

i розглядати одиниці, тобто будувати досконалу ДНФ, то конституенти $c_{2}^{1}=(010)$ і $c_{3}^{1}=(011)$ склеюються за змінною $x_{1}$, а $c_{5}^{1}=(101)$ і $c_{7}^{1}=(111)$ - за змінною $x_{2}$. Проте $c_{2}^{1}=(010)$ і $c_{5}^{1}=(101)$ не склеюються, хоча необхідна умова (8) виконується: $\left|\sigma_{i}-\sigma_{j}\right|=1$, але достатня умова (9) не задовольняється: $d_{H}\left(\sigma_{i}, \sigma_{j}\right)=3$. Однак $c_{3}^{1}=(011)$ і $c_{7}^{1}=(111)$ теж склеюються (за змінною $\left.x_{3}\right)$. Геометричну ілюстрацію можна побачити на тривимірному кубі (див. рис. 1).

У підсумку маємо скорочену ДНФ як диз'юнкцію простих імплікант:

$$
f\left(x_{1}, x_{2}, x_{3}\right)=\bar{x}_{3} x_{2} \vee x_{3} x_{1} \vee x_{2} x_{1} \text {. }
$$

Розглянуте нагадує знаходження скороченої ДНФ за методом Квайна Мак-Класкі як модифрікації метода Квайна: проведення всіх можливих неповних склеювань та поглинань.

Аналогічно діємо в разі знаходження скороченої КНФ. 


\section{4. Побудова скорочених і тупикових форм БФ}

Скорочені форми. Склеювання конституент одиниці або нуля здійснюється в такому порядку:

1) виписуємо за таблицею значень істинності БФ номери наборів $v$ значень змінних $x_{i}, i=\overline{1, n}$, на яких функція набуває значення 1 (0) у разі дослідження диз'юнктивної (кон'юнктивної) форми;

2) знаходимо суми значень аргументів для кожного номера $v$ :

$$
\sigma_{v}=\sigma(v)=\sum_{i=1}^{n} x_{i}(v)
$$

3) аналізуємо суми $\sigma(v)$ з метою встановлення того, для яких із них відстань Гаммінга дорівнює одиниці, тобто які конституенти склеюються;

4) записуємо диз'юнкцію (кон'юнкцію) отриманих елементарних кон'юнкцій (диз'юнкцій), тобто скорочену ДНФ (КНФ) заданої БФ.

Описаний підхід до побудови скорочених форм може бути застосований для функції будь-якої скінченної кількості змінних. Його перевага полягає в тому, що доводиться оперувати тільки номерами наборів - числами, а остаточний результат подається вже в запису через змінні-аргументи (див. (10)). Завдяки цьому програмування процесу не повинно викликати труднощів.

Тупикові форми. Уведемо до розгляду матрицю $M$ розміру $m \times n$, де $m-$ кількість простих імплікант або імпліцент, $n$ - кількість наборів $v$, на яких БФ набуває одиничних значень; подаються вони не буквами, а наборами з одиниць і нулів, які їм відповідають. Відсутність якоїсь змінної позначатимемо прочерком "-". Так, в умовах розглянутого прикладу (див. (10)) матриця $M$ має вигляд:

$$
M=\left|\begin{array}{l}
\bar{x}_{3} x_{2} \\
x_{3} x_{1} \\
x_{2} x_{1}
\end{array}\right|\left[\begin{array}{cccc}
0 & 1 & - & - \\
- & - & 1 & 1 \\
- & 1 & - & 1
\end{array}\right] \text { (самі імпліканти наводити не обов'язково). }
$$

Аналізуємо матрицю з метою відшукання тупикових фоорм. Для цього, як і в методі Карно, знаходимо набори імплікант (імпліцент), які накривають усі конституенти заданої БФ.

У прикладі це забезпечується першими двома імплікантами. Вони визначають мінімальну ДНФ:

$$
f_{\vee}^{*}=\bar{x}_{3} x_{2} \vee x_{3} x_{1}
$$

Зауваження. Доцільно використовувати прочерки "-" й у разі, коли йдеться про операцію поглинання: якщо з двох імплікант (імпліцент) одна містить одні і ті ж змінні у меншій кількості, то вона поглинає іншу.

Наприклад,

$\bar{x}_{4} x_{3} x_{2} x_{1} \vee x_{2} x_{1}=x_{2} x_{1}$, або інакше $(0111) \vee(--11)=(--11)$.

Канонічну мінімізацію БФ багатьох змінних $(n>3)$ за номерами наборів значень аргументів названо $v$-мінімізацією, або методом $v$-мінімізації.

Наостанок розглянемо приклад мінімізації БФ п'яти змінних, заданої номерами наборів $v$ значень іï аргументів, на яких вона набуває значень, що дорівнюють одиниці, тобто - із властивістю $f=1$ :

\begin{tabular}{|l|l|l|l|l|l|l|l|l|l|l|l|l|l|l|}
\hline$v \mid f=1$ & 0 & 1 & 2 & 10 & 11 & 14 & 15 & 16 & 17 & 18 & 26 & 27 & 30 & 31 \\
\hline
\end{tabular}


Розв'язання. За заданими номерами $v$ підраховуємо $\sigma(v)$ :

\begin{tabular}{|c|c|c|c|c|c|c|c|c|c|c|c|c|c|c|}
\hline$v \mid f=1$ & 0 & 1 & 2 & 10 & 11 & 14 & 15 & 16 & 17 & 18 & 26 & 27 & 30 & 31 \\
\hline$\sigma(v)$ & 0 & 1 & 1 & 2 & 3 & 3 & 4 & 1 & 2 & 2 & 3 & 4 & 4 & 5 \\
\hline
\end{tabular}

Аналізуємо другий рядок з метою проведення всіх можливих неповних склеювань і поглинань.

Для наочності випишемо не всі 32 набори v , а тільки задані 14 (у порядку зростання), і відповідні двійкові вектори:

\begin{tabular}{|c|c|c|c|c|c|c|c|}
\hline$v \mid f=1$ & 0 & 1 & 2 & 10 & 11 & 14 & 15 \\
\hline$\left(x_{5} x_{4} x_{3} x_{2} x_{1}\right)$ & 00000 & 00001 & 00010 & 01010 & 01011 & 01110 & 01111 \\
\hline$v \mid f=1$ & 16 & 17 & 18 & 26 & 27 & 30 & 31 \\
\hline$\left(x_{5} x_{4} x_{3} x_{2} x_{1}\right)$ & 10000 & 10001 & 10010 & 11010 & 11011 & 11110 & 11111 \\
\hline
\end{tabular}

Операцію склеювання двох конституент або імплікант (імпліцент) позначимо через $G(i, j)$, де $i, j$ - номери об'єктів, що склеюються; символ $G$ (можливо з індексами) від англ. Glue - клей.

Проведемо склеювання за змінною $x_{5}$ (прослідкуйте!):

$$
\begin{aligned}
& \begin{array}{l}
G_{1}(0,16)=(-0000) \\
G_{2}(1,17)=(-0001)
\end{array} \mid \Rightarrow G_{1,2}(-000-) \Rightarrow \bar{x}_{4} \bar{x}_{3} \bar{x}_{2} \text {. } \\
& \begin{array}{l}
G_{3}(0,16)=(-0000) \\
G_{4}(2,18)=(-0010)
\end{array} \mid \Rightarrow G_{3,4}(-00-0) \Rightarrow \bar{x}_{4} \bar{x}_{3} \bar{x}_{1} . \\
& \begin{array}{l}
G_{5}(10,26)=(-1010) \\
G_{6}(11,27)=(-1011)
\end{array} \mid \Rightarrow G_{5,6}(-101-), \\
& \begin{array}{l}
G_{7}(14,30)=(-1110) \\
G_{8}(15,31)=(-1111)
\end{array} \mid \Rightarrow G_{7,8}(-111-), \\
& \Rightarrow G_{5-8}(-1-1-) \Rightarrow x_{4} x_{2} \text {. }
\end{aligned}
$$

Далі дев'яте склеювання проведемо за змінною $x_{4}$, а потім - за $x_{5}$ :

$$
\begin{aligned}
& G_{9}(2,10)=(0-010) \\
& G_{10}(18,26)=(1-010)
\end{aligned} \mid \Rightarrow G_{9,10}(--010) \Rightarrow \bar{x}_{3} x_{2} \bar{x}_{1} .
$$

Усі 14 конституент беруть участь у склеюваннях, тому поглинаються отриманими імплікантами. До того ж $c_{2}^{1}=(00010)$ і $c_{18}^{1}=(10010)$ беруть участь ще у склеюванні $G_{4}(2,18)=(-0010)$. Це означає, що у підсумку маємо дві тупикові ДНФ, які й є мінімальними:

$$
f_{\vee}^{*}=\bar{x}_{4} \bar{x}_{3} \bar{x}_{2} \vee x_{4} x_{2} \vee \bar{x}_{4} \bar{x}_{3} \bar{x}_{1}, \quad f_{\vee}^{*}=\bar{x}_{4} \bar{x}_{3} \bar{x}_{2} \vee x_{4} x_{2} \vee \bar{x}_{3} x_{2} \bar{x}_{1} .
$$

Висновок: метод v-мінімізації БФ від п'яти і більшої кількості змінних вручну потребує значних зусиль, а тому виникає необхідність у розробленні програм для комп'ютерної реалізації методу.

Залучаючи $\sigma(v)$, для мінімізації БФ від чотирьох змінних крім карт Карно можна використовувати чотиривимірний куб (рис. 2) - тессеракт. 


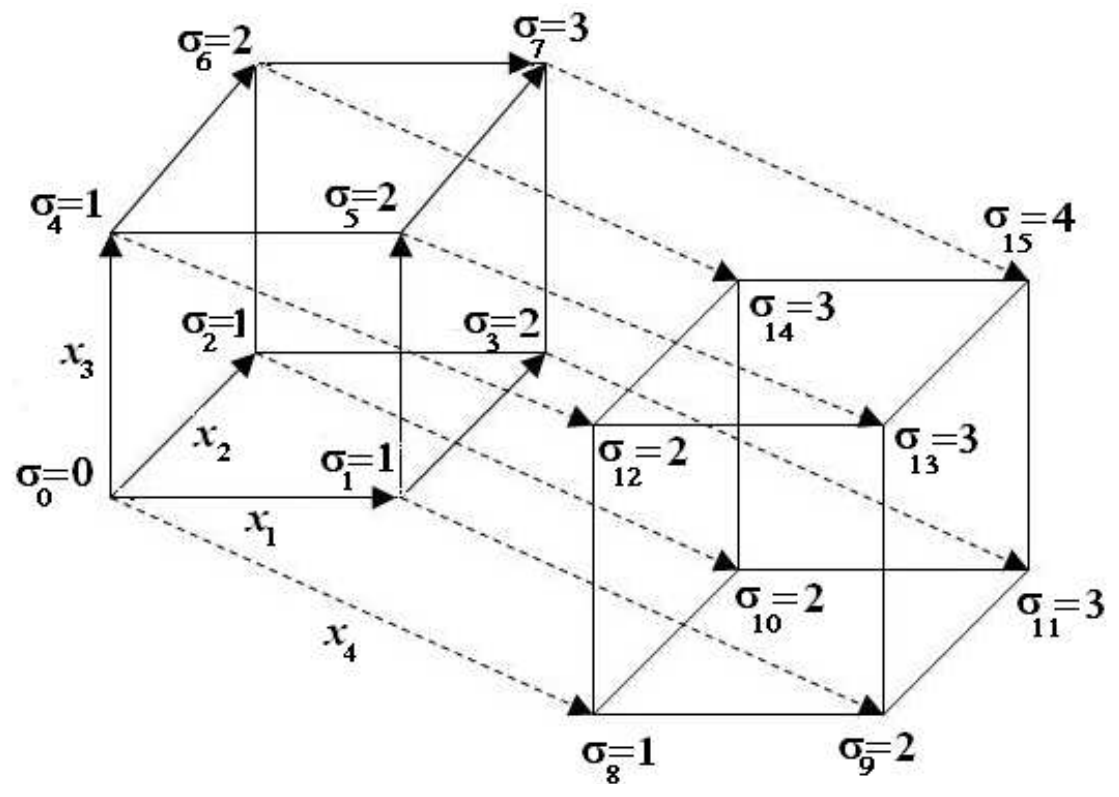

Рис. 2. Граф тессеракта, вершинам якого відповідають суми значень аргументів для кожного номера $v$

Двійкові набори значень змінних на рисунку не нанесено, вони легко відновлюються за індексами сигм, які $є$ номерами вершин графра. Усі конституенти нуля або одиниці, для яких різниці між сигмами на другому та першому (що вище) тривимірних кубах дорівнюють одиниці, склеюються. Склеюванню підлягають також усі конституенти, які належать одній грані тривимірних або чотиривимірного кубів. Ця обставина полегшує знаходження мінімальних ДНФ або КНФ.

Склеюються, наприклад, набори, для яких $\sigma_{3}=2$ i $\sigma_{7}=3$, бо вони належать одній грані тривимірного куба: $(0011) \uparrow(0111)=(0-11)-$ склеювання за третьою змінною. Одній грані тессеракта належать набори з сумами $\sigma_{7}=3$ i $\sigma_{15}=4$, тоді: $(0111) \uparrow(1111)=(-111)-$ склеювання за четвертою змінною.

\section{5. Про можливість мінімізації БФ у базисах, відмінних від базису $\left(\vee, \wedge,{ }^{-}\right)$}

У разі опису булевих змінних $x_{i}, i=\overline{1, n}$, як функцій від номерів наборів їхніх значень: $x_{i}=x_{i}(v), v \in\left\{0,1, \ldots, 2^{n}-1\right\}$, логічні операції можна подати через арифрметичні дії у вигляді формул [6]:

- інверсія: $\bar{x}_{i}(v)=1-x_{i}(v)$;

- кон'юнкція: $x_{i}(v) \wedge x_{j}(v)=x_{i}(v) \cdot x_{j}(v)$;

- диз'юнкція: $x_{i}(v) \vee x_{j}(v)=x_{i}(v)+x_{j}(v)-x_{i}(v) \cdot x_{j}(v)$;

- імплікація: $x_{i}(v) \Rightarrow x_{j}(v)=1-x_{i}(v)\left(1-x_{j}(v)\right)$ та ін.

Згідно з теоремою Поста повною $є$ система фрункцій $(\wedge, \oplus, 1)$, тобто кон'юнкція, додавання за модулем 2 (операція Жегалкіна), константа 1. Базис складають також операції: стрілка Пірса як інверсія диз'юнкції і штрих Шефрфера як інверсія кон'юнкції. Дослідження щодо використання цих базисів для мінімізації БФ поки що не проводилися. 
За допомогою операції Жегалкіна є можливість обчислювати відстань Гаммінга. Нехай $X(j)=\left(x_{1}(j), x_{2}(j), \ldots, x_{n}(j)\right)$ і $X(k)=\left(x_{1}(k), x_{2}(k), \ldots, x_{n}(k)\right)$ - кортежі змінних, де $j, k \in\left\{0,1,2, \ldots, 2^{n}-1\right\}-$ множина номерів наборів $v$. Тоді відстань Гаммінга

$$
d_{H}=d_{H}(X(j), X(k))=X(j) \oplus X(k)=\sum_{i=1}^{n}\left(x_{i}(j) \oplus x_{i}(k)\right) .
$$

Якщо взяти, наприклад, $n=5, j=10, k=27$, то

$$
X(10) \oplus X(27)=\oplus \frac{01010}{11011}=10001 \Rightarrow d_{H}=\sum_{i=1}^{5}\left(x_{i}(10) \oplus x_{i}(27)\right)=2 .
$$

3 метою зменшення кількості переборів спочатку слід перевірити, чи виконується теорема 1 (необхідна умова склеювання конституент).

\section{Висновки та перспективи}

Вивчення запропонованого підходу до мінімізації БФє доцільним, оскільки значення змінних, сама функція, набори значень змінних описуються аналітично тільки за допомогою номера набору $v$. 3 огляду на це забезпечується можливість застосування до мінімізації БФ цілочислового математичного програмування.

\section{Список літератури}

1. Поспелов, Д. А. Логические методы анализа и синтеза схем. Изд. 3-е, перераб. и доп. / Д. А. Поспелов. - Москва : Энергия, 1974. - 368 с.

2. Сенчуков, В. Ф. Основи дискретної математики : навч. посіб. / В. Ф. Сенчуков, Т. В. Денисова. - Харків : Вид. ХНЕУ, 2007. - 344 с.

3. Сенчуков, В. Ф. Логические операции над последовательностями и закон простых чисел / В. Ф. Сенчуков // Докл. АН УССР. Сер. А. - 1988. - № 6. C. 20-23.

4. Сенчуков, В. Ф. Логические свойства обобщенных арифметических прогрессий / В. Ф. Сенчуков // Докл. АН УССР. Сер. А. - 1988. - № 8. - С. 16-19.

5. Hamming, R. W. Error Detecting and Error Correcting Codes / R. W. Hamming // Bell System Technical Journal, Volume 29, Number 2, April, 1950, pp. 147-160.

6. Биркгоф, Г. Теория структур / Г. Биркгоф ; пер. с англ. М. И. Граева. Москва : ИЛ, 1952. -408 с.

\section{References}

1. Pospelov, D. A. Logicheskie metody analiza i sinteza sxem. Izd. 3-e, pererab. i dop. / D. A. Pospelov. - Moskva : E'nergiya, 1974. - 368 s.

2. Senchukov, V. F. Osnovy` dy`skretnoyi matematy`ky`: navch. posib. / V. F. Senchukov, T. V. Deny`sova. - Xarkiv : Vy`d. XNEU, 2007. - 344 s.

3. Senchukov, V. F. Logicheskie operacii nad posledovatel'nostyami i zakon prostyx chisel / V. F. Senchukov // Dokl. AN USSR. Ser. A. - 1988. - № 6. - S. 20-23.

4. Senchukov, V. F. Logicheskie svojstva obobshhennyx arifmeticheskix progressij / V. F. Senchukov // Dokl. AN USSR. Ser. A. - 1988. - № 8. - S. 16-19.

5. Hamming, R. W. Error Detecting and Error Correcting Codes / R. W. Hamming // Bell System Technical Journal, Volume 29, Number 2, April, 1950, pp. 147-160.

6. Birkgof, G. Teoriya struktur / G. Birkgof ; per. s angl. M. I. Graeva. - Moskva : IL, 1952. $-408 \mathrm{~s}$. 
Надійшла до редакції 04.02.2019, розглянута на редколегії 08.02.2019.

\section{Минимизация булевых функций по номерам наборов значений аргументов}

Предлагается оригинальный подход к аналитической канонической минимизации переключательных (булевых) функций, основанный на представлении булевых функций (БФ) в виде функции одной переменной - номера набора $\checkmark$ значений ее аргументов. Для этого с помощью фрункции Антье устанавливается зависимость (в виде формул) значений каждой из $n$ переменных от номера $v$. Для построения минимальной дизъюнктивной или конъюнктивной нормальной фоормы БФ отталкиваются от соответствующих совершенных форм. В связи с этим возникает необходимость описания последовательности номеров наборов, на которых переменные принимают значения 1 и 0 . Общие члены таких последовательностей могут быть получены с помощью фрормулы общего члена числовой последовательности в представлении через конечные разности ее членов. Далее устанавливается связь между суммой значений атомов (терм) $\sigma(v)$ и номерами их значений. C помощью значений $\sigma(v)$ решается вопрос о склеивании конституент единицы или нуля. Для БФ от трех и четырех переменных изображены соответственно трехмерный и четырехмерный кубы, вершины которых помечены сигмами. Поскольку необходимое условие склеивания конституент - модуль разности между сигмами равен единице - не является достаточным, то используется критерий склеивания: конституенты единицы или нуля склеиваются тогда и только тогда, когда расстояние Гамминга между двумя значениями $\sigma(v)$ равно единице. На основании описанных средств получен общий порядок склеивания конституент единицы или нуля. Для построения тупиковых форм используется матрица размера $m \times n$, где $m$ - количество простых импликант или имплицент, $n$ - количество наборов $v$, на которых БФ принимает значения 1 или 0 ; представляются они не буквами, а наборами из единиц и нулей, которые им соответствуют. Предложенный подход к минимизации БФ назван методом $v$-минимизации. Приведен пример минимизации БФ от пяти переменных, заданной номерами наборов $v$ значений ее аргументов, на которых она принимает значения, равные единице, то есть - со свойством $f=1$. Обсуждена возможность применения $v$-минимизации БФ в базисах, отличных от базиса $\left(\wedge, \vee,-{ }^{-}\right)$, и на перспективу - применение к минимизации БФ целочисленного математического программирования.

Ключевые слова: булева функция, метод минимизации, набор, операция, поглощение, склеивание, сокращенная форма, тупиковая фрорма.

\section{Minimization of Boolean functions by the numbers of sets of argument values}

An original approach to analytic canonical minimization of switching (Boolean) functions, which is based on the representation of Boolean functions (BF) as a function of one variable - the number of the set $v$ of values of its arguments, is proposed. For this, using the Antje function, the dependence (in the form of formulas) of the values of each of $n$ variables on the number $v$ is established. To construct a minimal disjunctive or conjunctive normal form of the BF are repelled from the corre- 
sponding perfect forms. In this connection the need to describe the sequence of numbers of sets, on which the variables take the values 1 and 0 , arises. The common terms of such sequences can be obtained using the formula for the common term of a numerical sequence in a representation through the finite differences of its members. Further the connection between the sum of the values of atoms (term) $\sigma(v)$ and the numbers of their values is established. With the help of the values of $\sigma(v)$, the question of gluing the constituents of the unit or zero is solved. Threedimensional and four-dimensional cubes whose vertices are labeled with sigmas are depicted for a function of three and four variables, respectively. Since the necessary condition for gluing the constituents - the modulus of the difference between sigmas is equal to one - is not sufficient, the gluing criterion is used: the constituents of a unit or zero are glued if and only if the Gamming distance between two values of $\sigma(v)$ is equal to one. The general order for gluing the constituent of a unit or zero on the basis of the described means is obtained. A matrix of size $m \times n$, where $m$ is the number of simple implicant or implicent, $n$ is the number of sets, on which the BF unit or zero values takes, is used to build deadlock forms; they are not represented by letters, but by sets of ones and zeros that correspond to them. The proposed approach to minimizing BF is called the $v$-minimization method. An example of minimizing of BF of five variables, given by the numbers of the sets $v$ of values of its arguments, on which it takes values equal to one, that is - with the property $f=1$, is given. The possibility of using the $v$-minimization of BF in bases other than the basis $(\wedge, \vee,-)$, and in the future - an application to the minimization of BF of integer mathematical programming is discussed.

Keywords: Boolean function, minimization method, set, operation, absorption, gluing, abbreviated form, deadlock form.

\section{Відомості про авторів:}

Сенчуков Віктор Федорович - кандидат фрізико-математичних наук, доцент кафедри вищої математики та економіко-математичних методів Харківського національного економічного університету імені Семена Кузнеця (61166, Україна, м. Харків, пр. Науки, 9a, e-mail: viktor.senchukov@hneu.net).

Денисова Тетяна Володимирівна - кандидат технічних наук, доцент кафедри вищої математики та економіко-математичних методів Харківського національного економічного університету імені Семена Кузнеця (61166, Україна, м. Харків, пр. Науки, 9a, e-mail: tetiana.denysova@hneu.net).

\section{About the Authors:}

Senchukov Viktor - Candidate of Physical and Mathematical Sciences, Associate Professor of the Department of Higher Mathematics and EconomicMathematical Methods of the Kharkov National Economic University named after Symon Kuznets (61166, Ukraine, Kharkov, Nauki ave., 9a, e-mail: viktor.senchukov@hneu.net). ORCID : 0000-0002-5402-7554.

Denysova Tatyana - Candidate of Technical Sciences, Associate Professor of the Department of Mathematics and Economic-Mathematical Methods of the Kharkov National Economic University named after Symon Kuznets (61166, Ukraine, Kharkov, Nauki ave., 9a, e-mail: tetiana.denysova@hneu.net). ORCID : 0000-00017254-0901. 